\title{
Limb abnormalities on trisomy 18: evidence for early diagnosis
}

\author{
Rafael F. M. Rosa, ${ }^{1}$ Rosana Cardoso Manique Rosa, ${ }^{2}$ Marina Boff Lorenzen, ${ }^{3}$ \\ Paulo R. G. Zen, ${ }^{4}$ Ceres A. V. de Oliveira, ${ }^{5}$ Carla Graziadio, ${ }^{6}$ Giorgio A. Paskulin ${ }^{7}$
}

\begin{abstract}
Objective: To assess the frequency and types of limb abnormalities observed among patients with trisomy 18 , or Edwards syndrome (ES).

Method: The sample consisted of consecutive patients evaluated by a clinical genetics service in the period from 1975 to 2008. The results of the cytogenetic analysis, as well as the clinical data were retrieved from the medical records, with special attention to limb abnormalities findings. All the karyotype analysis was performed at the same laboratory.

Results: During the study period, 50 patients were identified, $33(66 \%)$ of them females, with ages at the first evaluation ranging from 1 day to 16 years (median 14 days). The single lineage with free trisomy 18 was the most frequent chromosomal disorder (90\%). Mosaicism was observed in $10 \%$ of the cases. Clenched fist with overlapping fingers was the predominant anomaly of the upper limbs (70\%). Other common disorders included the single palmar crease (42\%) and hypoplastic nails (36\%). Radial abnormalities were found in 11 patients (22\%). As for the lower limbs, hypoplastic nails were the most common abnormality $(58 \%)$, followed by the rocker bottom foot with prominent calcaneus $(50 \%)$. One patient had unilateral ectrodactyly as well.

Conclusions: Despite the classical description, limb anomalies can be much variable in ES. Some patients may show unusual abnormalities, such as radial defects and ectrodactyly. These findings are extremely important for the clinical suspicion and early identification of patients with ES.
\end{abstract}

J Pediatr (Rio J). 2012;88(5):401-5: Chromosomes, human, pair 18, trisomy, chromosome aberrations, extremities.

\section{Introduction}

Trisomy 18, or Edwards syndrome (ES), is considered a relatively common chromosomal disorder, which is observed in one of every $3,600-8,500$ live births. It is characterized by a broad clinical picture that frequently includes multiple malformations, and an ominous prognosis. ${ }^{1}$ To date, more than 130 abnormalities have already been described, but none of them is present in $100 \%$ of the patients. Limb anomalies, however, are prominent. ${ }^{2}$

1. PhD. Programa de Pós-Graduação em Patologia, Universidade Federal de Ciências da Saúde de Porto Alegre (UFCSPA), Porto Alegre, RS, Brazil. Invited professor, Programa de Pós-Graduação em Patologia, UFCSPA, Porto Alegre, RS, Brazil.

2. MSc. Programa de Pós-Graduação em Patologia, UFCSPA, Porto Alegre, RS, Brazil.

3. Medical student, UFCSPA, Porto Alegre, RS, Brazil.

4. PhD. Programa de Pós-Graduação em Patologia, UFCSPA, Porto Alegre, RS, Brazil. Professor, Disciplina de Genética Clínica, Programa de Pós-Graduação em Patologia, UFCSPA, Porto Alegre, RS, Brazil.

5. MSc. Engenharia de Produção, Universidade Federal do Rio Grande do Sul (UFRGS), Porto Alegre, RS, Brazil.

6. PhD candidate. Programa de Pós-Graduação em Patologia, UFCSPA, Porto Alegre, RS, Brazil. Professor, Disciplina de Genética Clínica, UFCSPA, Porto Alegre, RS, Brazil.

7. PhD. Genética Molecular, Programa de Pós-Graduação, UFRGS, Porto Alegre, RS, Brazil. Professor, Disciplina de Genética Clínica, UFCSPA, Porto Alegre, RS, Brazil. Coordinator, Programa de Pós-Graduação em Patologia, UFCSPA, Porto Alegre, RS, Brazil.

No conflicts of interest declared concerning the publication of this article.

Financial support: Coordenação de Aperfeiçoamento de Pessoal de Nível Superior (CAPES) and Programa de Iniciação Científica da Universidade Federal de Ciências da Saúde de Porto Alegre (PIC-UFCSPA).

Suggested citation: Rosa RF, Rosa RC, Lorenzen MB, Zen PR, de Oliveira CA, Graziadio C, et al. Limb abnormalities on trisomy 18: evidence for early diagnosis. J Pediatr (Rio J). 2012;88(5):401-5.

Manuscript submitted Apr 21 2012, accepted for publication May 282012.

http://dx.doi.org/10.2223/JPED.2212 
Thus, the present study aimed to assess the frequency and types of limb abnormalities observed among patients with ES.

\section{Methods}

The sample was constituted of consecutive patients evaluated in genetic clinic of a reference hospital in the south of the country, in the period from 1975 to 2008. The results of the cytogenetic analysis, as well as clinical data, were retrieved from the medical charts, with special focus on limb abnormalities. The study was approved by the Hospital Research Ethics Committee.

All the patients had the karyotype analysis performed at the Cytogenetic Laboratory of the Universidade Federal de Ciências da Saúde de Porto Alegre. Briefly, this test includes the performance of a cell culture with lymphocytes stimulation using phytohemagglutinin, hypotonic shock, cell fixation with Carnoy solution, slides preparation and $\mathrm{G}$ banding staining with trypsin and Giemsa. All the slides analysis was done using an Axioskop Zeiss microscope, by counting a mean of 26 metaphasic plaques in each case (the number ranging from 6 to 40 ).

Data analysis was performed with the PEPI (Programs for EPIdemiologists) software (version 4.0) using the twotailed Fisher's exact test for comparison of frequencies. $P$ values $<0.05$ were considered significant.

\section{Results}

In the evaluation period, we identified 50 patients with ES, 33 (66\%) females. The patients' ages at the first evaluation ranged from 1 day to 16 years (74\% under one month of age, median 14 days). Regarding the karyotype findings, the most common disorder was the single lineage with free trisomy 18, which was observed in 45 patients (90\%). Two (4.4\%) of these 45 patients also had trisomy $X$, and one $(2.2 \%)$ an associated der $(13 ; 14)$. Mosaicism was identified in five patients $(10 \%)$, with almost all of them presenting one lineage with free trisomy 18 associated with a normal one. In one case only there was a third lineage with double aneuploidy: free trisomy 18 associated with the $\mathrm{XXY}$ constitution.

The most frequent abnormality observed in the upper limbs in our sample $(n=50)$ was the clenched fists with overlapping fingers (campodactyly or contractures) (70\%). Radial abnormalities were found in 11 patients (22\%). As for the lower limbs, hypoplastic nails were the most common finding ( $58 \%$ ), followed by the rocker-bottom foot with prominent calcaneus (50\%). One of the patients had unilateral ectrodactyly (lobster claw foot) (Table 1). Figure 1 shows the clenched fists with predominant overlapping of the second over the third finger (in A), and foot with short hallux, hypoplastic nails and partial syndactyly of the second and third toes (in B).
To assess whether the presence of mosaicism could influence the frequency of limb abnormalities, we compared the main findings between patients with and without mosaicism. The most frequent findings were the clenched fists with overlapping fingers, hypoplasia of the toenails, and rocker-bottom foot with prominent calcaneus. There were no significant statistical differences between the groups, but a trend towards significance $(p=0.0502)$ was observed for the last finding.

\section{Discussion}

In spite of the classical description, limb abnormalities found in ES are highly variable. In our sample, only about one fourth (28\%) of the patients had more than one of the major limb abnormalities simultaneously, seen in more than $50 \%$ of the cases (Table 1 ). Clenched fists with overlapping fingers (usually the second over the third and the fifth over the fourth finger) are the main abnormality described, and the one that usually leads to the clinical suspicion of ES (Table 1). ${ }^{3-10}$ This finding gets the maximum number of points (out of 5 ) in the score of Marion et al., ${ }^{3}$ a tool that was developed with the aim of improving the identification of patients with ES in the neonatal period.

In our study, only $70 \%$ of the patients had clenched fists with overlapping fingers. This abnormality has also been reported in the literature as occurring from 58 to $96 \%$ of the cases (usually over 90\%) (Table 1).4-10 Our analysis, however, shows that a considerable number of patients with ES do not present this finding. ${ }^{4-10}$ Furthermore, this feature is neither characteristic nor pathognomonic, as it has been reported in other conditions that comprise the differential diagnosis of ES, such as trisomy 13 (Patau syndrome). ${ }^{2}$ Other common findings in this study, which have also been reported in the literature, are the single palmar crease (18$61 \%)$ and hypoplastic nails (13-96\%). Nevertheless, the high variability in the frequency of these findings reported in the studies should be highlighted. ${ }^{4-10}$ The lack of the distal digital crease also seems to be frequent (observed in $28 \%$ of our patients), but given little importance in the evaluation of the patients. The same applies to the presence of an arches pattern on the digital pulps of six or more fingers (with reported frequencies usually higher than 90\%).4-10 To evaluate this feature, the use of stamp ink and paper, or even a magnifying glass may be necessary. In our study, this feature could not be evaluated. Both changes, the lack of the distal phalangeal crease and the arch pattern on the digital pulps, represent dermatoglyphic disturbances (which also include the sole palmar crease) and get the maximum number of points in the score of Marion et al. ${ }^{3}$

Some patients can also present unusual abnormalities, such as radial defects and ectrodactyly. Radial alterations have also shown to be highly variable. The most common reported anomaly is the abnormal implantation of the thumb. 
Other findings in our study, which have also been reported in other case series, were the hypoplasia or agenesis of the thumb and the radius (Table 1 ). ${ }^{4-11}$ One of our patients with radial abnormalities has been described in detail by Zen et al. ${ }^{12}$ Polydactitly of the fingers, an unusual finding, was not observed in our sample (Table 1).4-10

For the lower limbs, nails hypoplasia and rocker bottom feet with prominent calcaneus represent important findings. ${ }^{4-10}$ They get 5 and 3 points, respectively, in the score of Marion et al. ${ }^{3}$ Other relatively common findings are the syndactyly of the toes (particularly of the second and third toes), clubfoot, and hallux abnormalities (short and dorsiflexed hallux). However, as shown in Table 1, there is a high variability in the frequency of these findings in the literature. ${ }^{4-10}$ Congenital hip dislocation was observed in 6\% of our patients, but it may have been underdiagnosed, as Hodes at al. have found it in $62 \%$ of individuals with ES. ${ }^{6}$ In those reports, ectrodactyly is considered a very rare finding, which has been described in a few case reports only (our study is the first case series to report such finding) (Table 1). In those reports, as in our patient, ectrodactyly was observed in the lower limbs. ${ }^{13}$ Severe longitudinal deficiencies of the lower limbs, such as agenesis of the toes, have been described in case reports or small case series. ${ }^{14}$

Table 1 - Abnormalities of the upper and lower limbs observed in the sample in comparison with the literature (\%)

\begin{tabular}{|c|c|c|c|c|c|c|c|c|c|}
\hline Studies & $\begin{array}{l}\text { Marion } \\
\text { et al. }{ }^{3} \\
\text { score }\end{array}$ & $\begin{array}{l}\text { Present } \\
\text { study } \\
(n=50)\end{array}$ & $\begin{array}{l}\text { Taylor }^{4} \\
(\mathrm{n}=27)\end{array}$ & $\begin{array}{c}\text { Le Marec } \\
\text { et al..5 } \\
(n=20)\end{array}$ & $\begin{array}{c}\text { Hodes } \\
\text { et al. }{ }^{6} \\
(n=29)\end{array}$ & $\begin{array}{c}\text { Kinoshita } \\
\text { et al. }{ }^{7} \\
(n=31)\end{array}$ & $\begin{array}{c}\text { Sugayama } \\
\text { et al. } 8 \\
(n=24)\end{array}$ & $\begin{array}{c}\text { Lin } \\
\text { et al. }{ }^{9} \\
(n=39)\end{array}$ & $\begin{array}{c}\text { Hsiao } \\
\text { et al. }{ }^{10} \\
(n=31)\end{array}$ \\
\hline \multicolumn{10}{|l|}{ Upper limbs } \\
\hline Clenched fist with overlapping fingers & 5 & 70 & 89 & 95 & 90 & $>50$ & 96 & 95 & 58 \\
\hline Single palmar crease & 3 & 42 & 61 & - & - & $<50$ & - & 18 & - \\
\hline Hypoplastic nails & 5 & 36 & 63 & 30 & 48 & $<50$ & 96 & 13 & - \\
\hline Lack of the distal digital crease & 5 & 28 & - & 40 & - & - & 13 & - & - \\
\hline Clinodactyly & - & 22 & - & - & 10 & - & - & - & - \\
\hline Clasped thumb & - & 14 & - & - & - & - & - & - & - \\
\hline Ulnar or radial hand dislocation & 3 & 12 & - & - & - & - & - & - & 13 \\
\hline Abnormal implantation of the thumb & - & 8 & 52 & - & - & - & - & - & - \\
\hline Radial hypoplasia & - & 6 & - & - & 3 & - & - & - & - \\
\hline Thumb hypoplasia & 3 & 4 & - & - & 3 & - & - & $\leq 3$ & $? / 29$ \\
\hline Agenesis of the thumb & 3 & 4 & - & - & - & - & - & $\leq 3$ & $? / 29$ \\
\hline Triphalangeal thumb & - & 4 & - & - & - & - & - & - & - \\
\hline Sessile thumb & - & 2 & - & - & - & - & - & - & - \\
\hline Agenesis of the radius & 1 & 2 & - & - & 3 & 3 & - & - & - \\
\hline Syndactytly & 3 & 2 & $? / 32$ & - & $? / 14$ & $<50$ & - & $\leq 3$ & $? / 26$ \\
\hline Polydactyly & - & - & 8 & 5 & 3 & $<50$ & - & $\leq 3$ & - \\
\hline Presence of $\geq 6$ arches on the digital pulps & 5 & $\mathrm{NE}$ & 96 & 64 & - & - & 96 & - & - \\
\hline \multicolumn{10}{|l|}{ Lower limbs } \\
\hline Hypoplastic nails & 5 & 58 & 63 & 30 & 48 & $<50$ & 96 & 13 & - \\
\hline Rocker-bottom foot with prominent calcaneus & 3 & 50 & 77 & 70 & 48 & $<50$ & - & 90 & 52 \\
\hline Sindactyly of the toes & 3 & 16 & $? / 32$ & - & $? / 14$ & $<50$ & - & $\leq 3$ & $? / 26$ \\
\hline Clubfoot & 3 & 14 & 8 & 10 & 28 & $<50$ & 13 & - & - \\
\hline Short hallux & 5 & 14 & $? / 75$ & - & 10 & $<50$ & - & - & 22 \\
\hline Dorsiflexion of the hallux & - & 10 & $? / 75$ & 45 & - & $<50$ & 83 & - & - \\
\hline Enlarged space among the toes & - & 8 & - & - & 10 & - & - & - & - \\
\hline Congenital hip dislocation & 1 & 6 & - & - & 62 & - & - & - & - \\
\hline $\begin{array}{l}\text { Deep crease between the hallux } \\
\text { and the second toe }\end{array}$ & - & 6 & - & - & - & - & - & - & - \\
\hline Overlapping fingers & - & 6 & - & - & - & - & - & - & - \\
\hline Hallux valgus & - & 4 & - & - & - & - & - & - & - \\
\hline Large hallux & - & 4 & - & - & - & - & - & - & - \\
\hline Feet edema & - & 2 & - & - & - & - & - & - & - \\
\hline Ectrodactyly & 1 & 2 & - & - & - & - & - & - & - \\
\hline
\end{tabular}

$?=$ not determined; $\mathrm{NE}=$ not evaluated. 

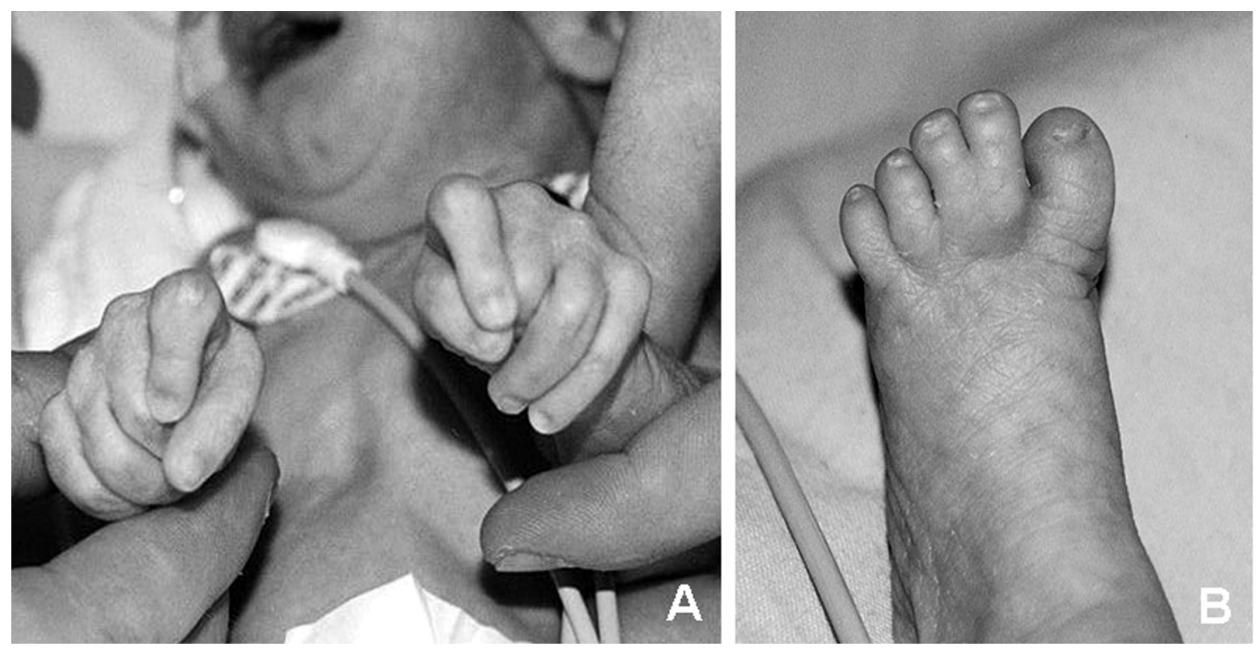

Figure 1 - Limb anomalies observed among the patients

In our review of the literature, we did not find any comparison in the limb findings between patients with ES with and without mosaicism. Although our sample is the largest reported in the literature (Table 1), we believe that the small number of patients with mosaicism $(n=5)$ may have limited our analysis. Anyway, we did not observe significant differences in the frequency of the main limb abnormalities observed.

In a clinical pathological study, Ramirez-Castro \& Bersu ${ }^{15}$ reported the limb anatomic variations observed in 8 children with ES. The authors observed an influence on the development of the pre-axial component of the upper limbs and a trend to longitudinal deficiency defects. The anomalies reported included muscle defects along the radial margin of the forearm and hand, agenesis of a definitive musculocutaneous nerve in all the limbs, and reduction of the radial artery. They suggested that the abnormalities observed could be explained by certain pathogenic mechanisms, such as a defect in the development of the peripheral nerve and tissue necrosis. ${ }^{15}$ Therefore, the recognition and understanding of the variability of limb abnormalities are essential for the early identification of the patients with ES. This is of fundamental importance for the pediatricians (particularly, the neonatologists) who are usually the first health professionals to evaluate these patients. The definition of the diagnosis has important implications in the management and genetic counseling of the patients and their families. Recurrence of the trisomy 18 is considered to be rare. Nevertheless, when the trisomy 18 occurs as a consequence of translocations, a chromosomal study of the parents is indicated, as one of them can carry a balanced chromosome rearrangement, which poses a higher risk for the future offspring.

\section{Acknowledgements}

We thank the Brazilian Federal Agency for Support and Evaluation of Graduate Education (Coordenação de Aperfeiçoamento de Pessoal de Nível Superior-CAPES) for the scholarship received.

\section{References}

1. Rosa RF, Rosa RC, Lorenzen MB, de Moraes FN, Graziadio C, Zen PR, et al. Trisomy 18: experience of a reference hospital from the south of Brazil. Am J Med Genet A. 2011;155A:1529-35.

2. Jones KL. Smith's recognizable patterns of human malformation. 6th ed. Philadelphia, PA: Elsevier Saunders; 2006.

3. Marion RW, Chitayat D, Hutcheon RG, Neidich JA, Zackai EH, Singer LP, et al. Trisomy 18 score: a rapid, reliable diagnostic test for trisomy 18. J Pediatr. 1988;113:45-8.

4. Taylor AI. Autosomal trisomy syndromes: a detailed study of 27 cases of Edwards' syndrome and 27 cases of Patau's syndrome. J Med Genet. 1968;5:227-52.

5. Le Marec BM, Lair JC, Kérisit J, Le Mée F, Sénécal J. 20 cases of trisomy 18 . Sex-ratio in relation to age of the mother. Ann Pediatr (Paris). 1977;24:125-36.

6. Hodes ME, Cole J, Palmer CG, Reed T. Clinical experience with trisomies 18 and 13. J Med Genet. 1978;15:48-60. 
7. Kinoshita M, Nakamura $\mathrm{Y}$, Nakano R, Morimatsu M, Fukuda S, Nishimi $Y$, et al. Thirty-one autopsy cases of trisomy 18 : clinical features and pathological findings. Pediatr Pathol. 1989;9:445-57

8. Sugayama SM, Kim CA, Utagawa CY, Albano LM, Bertola DR, Koiffmann $\mathrm{CP}$, et al. Estudo genético-clínico de 24 pacientes com trissomia 18 (síndrome de Edwards). Pediatria (São Paulo). $1999 ; 21: 133-43$

9. Lin HY, Lin SP, Chen $\mathrm{YJ}$, Hung $\mathrm{HY}, \mathrm{Kao} \mathrm{HA}, \mathrm{Hsu} \mathrm{CH}$, et al. Clinical characteristics and survival of trisomy 18 in a medical center in Taipei, 1988-2004. Am J Med Genet A. 2006;140:945-51.

10. Hsiao CC, Tsao LY, Chen HN, Chiu HY, Chang WC. Changing clinical presentations and survival pattern in trisomy 18. Pediatr Neonatol. 2009;50:147-51.

11. Sugayama SM, Kim CA, Barba MF, Albano LM, Bertola DR, Utagawa $\mathrm{CY}$, et al. Síndrome de Edwards com aplasia radial - relato de dois casos e revisão das anomalias esqueléticas na síndrome. Radiol Bras. 2000;33:241-7.

12. Zen PR, Rosa RF, Rosa RC, Dale Mulle L, Graziadio C, Paskulin GA. Unusual clinical presentations of patients with Patau and Edwards syndromes: a diagnostic challenge? Rev Paul Pediatr. 2008;26:295-9.
13. Rogers RC. Trisomy 18 with unilateral atypical ectrodactyly. Am J Med Genet. 1994;49:125-7.

14. Christianson AL, Nelson MM. Four cases of trisomy 18 syndrome with limb reduction malformations. J Med Genet. 1984;21:293-7.

15. Ramirez-Castro JL, Bersu ET. Anatomical analysis of the developmental effects of aneuploidyin man - the 18-trisomy syndrome: II. Anomalies of the upper and lower limbs. Am J Med Genet. 1978;2:285-306.

\section{Correspondence:}

Giorgio Adriano Paskulin

Rua Sarmento Leite, 245/403, Centro

CEP 90050-170 - Porto Alegre, RS - Brazil

Tel.: +55 (51) 3303.8771

Fax: +55 (51) 3303.8810

E-mail: paskulin@ufcspa.edu.br 